\title{
The prognostic role of EZH2 expression in rectal cancer patients treated with neoadjuvant chemoradiotherapy
}

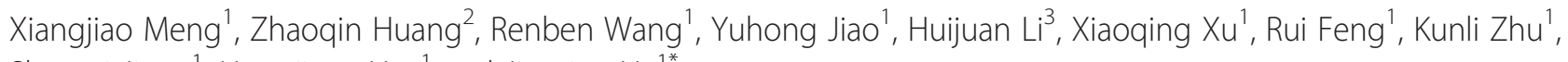
Shumei Jiang ${ }^{1}$, Hongjiang $\mathrm{Yan}^{1}$ and Jinming $\mathrm{Yu}^{1 *}$

\begin{abstract}
Background: Neoadjuvant chemoradiotherapy (nCRT) combined with surgery has been implemented as a standard treatment strategy in locally advanced rectal cancer (LARC). However, there is a wide spectrum of response to nCRT. The aim of this study was to determine whether enhancer of zeste homologue 2 (EZH2) expression could predict response to $\mathrm{nCRT}$ and outcomes for patients in LARC.

Method: The study examined the EZH2 expression in 112 biopsies by immohistochemistry. The associations between EZH2 and clinical characters were analyzed.

Results: EZH2 expression in biopsy tissue was significantly related to increased tumor cell proliferation, as assessed by Ki-67 expression with a cutoff value of $37 \%(p<0.001)$. High EZH2 expression was correlated closely with low differentiation ( $p=0.029)$, high CEA level $(p=0.041)$, T4 status $(p=0.011)$ and node metastasis $(p=0.045)$. By univariate and multivariate analysis, we observed low EZH2 expression could reliably and independently predict the good response to $\mathrm{nCRT}(\mathrm{p}=0.026$ and $p=0.023$ ) and down-staging ( $p=0.021$ and $p=0.027$ ). In univariate analysis, high EZH2 expression was significantly associated with poor 5 -year disease-free survival $(p=0.025)$ and 5 -year overall survival $(p=0.032)$. In multivariate analysis, $E Z H 2$ was a prognostic factor for 5 -year DFS $(H R=2.287 ; 95 \%$ $\mathrm{Cl} 1.137-4.602, \mathrm{p}=0.020)$ but not for 5 -year OS ( $\mathrm{HR}=2.182 ; 95 \% \mathrm{Cl} 0.940-5.364, \mathrm{p}=0.069)$.

Conclusion: Our study revealed that low EZH2 expression in biopsy tissue might be a useful predictive factor of good tumor response to nCRT and longer 5-year DFS in patients with LARC. However this is a relatively small retrospective study, to further validate the role of EZH2 in rectal cancer, large consistent cohort studies are needed.
\end{abstract}

Keywords: Rectal cancer, EZH2, Neoadjuvant chemoradiotherapy, Tumor response, Prognosis

\section{Background}

Rectal cancer is one of the leading causes of cancerrelated mortality and morbidity in the world [1]. Over the last two decades, advances in new treatment strategies have contributed significantly to the improvement of local recurrence and overall survival rate in patients with locally advanced rectal cancer (LARC) [2,3]. Evidences from randomized clinical trials strongly support the treatment of rectal cancer with neoadjuvant chemoradiotherapy

\footnotetext{
* Correspondence: sdyujinming@126.com

${ }^{1}$ Department of Radiation Oncology of Shandong Cancer Hospital and Institute, No. 440 Jiyan Road, Jinan, Shandong 250117, China Full list of author information is available at the end of the article
}

(nCRT) and surgery $[4,5]$. Due to the heterogeneous responses to nCRT, identifying a predictive or prognostic molecular marker is important to discriminate those patients who would benefit from nCRT and avoid unnecessary treatment with toxic side effects.

Enhancer of zeste homologue 2 (EZH2), as a member of the polycomb group of genes has important functions in tumor aggressiveness [6]. Its amplification was first studied in hematologic malignancies [7]. Disruption of EZH2 expression was observed to correlate closely with tumor aggressiveness and/or poor patient prognosis in prostate [8], oral [9], bladder [10], esophageal [11], breast [12] and ovarian cancers [13]. EZH2 is a cell cycle 
regulator and the expression of EZH2 delays upon tissue maturation and differentiation [14]. Over-expression of EZH2 was also observed to shorten the G1 phase of the cell cycle and lead to accumulation of cells in the $S$ phase [15], which might play a critical role in radioresistance $[11,16]$. Furthermore, as an essential downstream target of pRB/E2F pathway, EZH2 is a critical mediator of E2F function [15]. E2F1 has been observed to be associated with radiosensitivity and/or chemosensitivity in certain types of tumors [17-19]. In esophageal squamous cell carcinoma (ESCC), high EZH2 expression was significantly correlated with lack of clinical complete response to CRT $(\mathrm{p}=0.028)$ and poor disease-specific survival $(\mathrm{p}<0.001)$ [11]. In atypical teratoid/rhabdoid tumor (ATRT), targeted disruption of EZH2 by RNAi or pharmacologic inhibition strongly impaired cell growth, suppressed cell self-renewal, induced apoptosis, and potently sensitized these cells to radiation [16].

However, there is limited study concentrating on the predicting role of EZH2 in LARC. In the present study we examined the expression of EZH2 protein in pretreatment biopsies by immunohistochemistry (IHC), so as to determine whether EZH2 expression has predictive value of nCRT response and prognosis in patients with LARC.

\section{Materials and methods}

\section{Patients and clinical assessment}

The clinicopathological characteristics were reviewed retrospectively for the purpose of the study. All patients were diagnosed with primary rectal adenocarcinoma confirmed by rigid rectoscopy. Before treatment, tumor-nodemetastasis (TNM) stage was determined by a series of examination including physical examination, carcinoembryonic antigen (CEA) serum level, chest computed tomography (CT), contrast-enhanced CT and/or magnetic resonance imaging (MRI) of the abdomen and pelvis. TNM stages were reported according to the American Joint Committee on Cancer (AJCC) [20]. Informed consents were obtained from all patients and the research protocols were approved by the Ethics Committee of Shandong Cancer Hospital and Institute.

\section{Multimodal treatment}

112 patients received concurrent chemotherapy and radiotherapy followed by surgery. In brief, patients underwent whole pelvis preoperative radiotherapy with a dose of 50.4 Gy in 28 fractions using three-dimensional conformal irradiation or four-field box technique. Concurrent chemotherapy regimens include continuous infusion of 5 -fluorouracil \pm oxaliplatin or capecitabine \pm oxaliplatin. Four to six weeks after the completion of nCRT, total mesorectal excision (TME) was performed.

\section{Pathologic assessment}

Histopathologic examination was performed by two pathologists who were blinded for all clinical data. Pathologic TNM staging was performed on the surgical specimens to assess for tumor down-staging according to the current classification [20].

Tumor response was also evaluated using the tumor regression grade (TRG) system proposed by Dworak et al. [21]. Details as follows: grade 0, no regression; grade 1 , minor regression; grade 2, moderate regression; grade 3 , good regression; and grade 4 , total regression, no viable tumor cells. In the present study, TRG 3 and 4 were defined as "good response" while TRG 0-2 were defined as "poor response."

\section{Immunohistochemistry}

Tumor samples were collected from pretreatment tumor biopsies in 112 patients who received nCRT. The EZH2 and Ki-67 status was assessed using paraffin-embedded tissue samples that were cut into $5 \mu \mathrm{m}$ slices. The process of staining was performed according to the product protocol. Briefly, all sections were deparaffinized in xylene and rehydrated with distilled water through a graded series of ethanol solutions. Antigen retrieval was performed under high pressure for 2 minutes. Nonspecific binding was blocked by the application of serum at $37^{\circ} \mathrm{C}$ for 15 minutes (Beijing Zhongshan Golden Bridge Biotechnology Company, Beijing, China). For EZH2, the sections were stained with primary monoclonal rabbit anti-human EZH2 antibody ( Abcam, Cambridge, UK) in humidified chamber at $37^{\circ} \mathrm{C}$ for 60 minutes, with a diluted ratio of 1:200. Secondary goat anti-rabbit antibody was incubated at $37^{\circ} \mathrm{C}$ for 30 minutes (Beijing Zhongshan Golden Bridge Biotechnology Company, Beijing, China). For Ki-67, the sections were stained with primary monoclonal mouse anti-human Ki-67 antibody (Beijing Zhongshan Golden Bridge Biotechnology Company, China) in humidified chamber at $37^{\circ} \mathrm{C}$ for 60 minutes, with a diluted ratio of $1: 100$. Secondary goat anti-mouse antibody was incubated at $37^{\circ} \mathrm{C}$ for 30 minutes. Both EZH2 and Ki-67 expression were visualized using 3,3'-diaminobenzidine (DAB) and subsequently counterstained with hematoxylin.

Two independent observers who were blinded to the clinicopathologic parameters performed scoring using a previously validated scoring system for EZH2 expression $[10,11,22,23]$. This system scores nuclear EZH2 expression by recording the percentage of positive nuclei staining for the EZH2 protein, irrespective of staining intensity. EZH2 staining was classified into 2 groups: high expression, when at least $50 \%$ of the cells showed positive immunoreactivity in the nuclei and low expression, when positive cells were less than $50 \%$. For Ki-67 immunohistochemistry, the percentage of positive nuclei staining tumor cells was assessed in five representative 
visual fields. A cutoff was then chosen at the median value, dividing the samples in low or high nuclear Ki-67 expression.

\section{Follow-Up}

Patients underwent a standardized post-treatment followup including physical examinations, CEA serum level, peripheral blood cell count, chest X-ray, every 3 months for the first 2 years and every 6 months thereafter. Patients also underwent abdominal and pelvic CT or MRI every 6 months. Colonoscopy was performed within 1 year after treatment and then once every 2-3 years. The median follow-up was 56 months.

\section{Statistical analysis}

For all the statistical analysis, Statistical Product and Service Solutions (SPSS17.0) was used. The chi-squared test was also performed to assess the association between pathologic factors including EZH2 expression and tumor response. A multivariate stepwise logistic regression analysis was performed in order to determine the independent prediction of all variables that were significant in the univariate analysis. The associations between EZH2 protein expression and $\mathrm{Ki}-67$ was also analyzed by Chi-square test. For survival analysis, overall survival (OS) was defined as the time from diagnosis to death from any causes and was censored at the date of last contact for surviving patients. Disease free survival (DFS) was defined as the time from diagnosis to any evidence of local or systemic cancer recurrence. The impact of the EZH2 status on OS and DFS was determined using Kaplan-Meier method for the univariate survival analysis and Cox proportional hazards model for the multivariate survival analysis. The $\mathrm{p}$ values $<0.05$ was considered statistically significant differences.

\section{Results}

\section{Patient characteristics}

The clinicopathological parameters of the 112 patients was detailed in Table 1 . There were 62 cases assessed as clinical T3 (cT3) while 50 cases as clinical T4 (cT4) and 38 patients assessed as clinical N0 (cN0) while 74 patients assessed as $\mathrm{cN}+$. There were 52 cases with $\mathrm{CEA}<3.4 \mathrm{ng} /$ $\mathrm{ml}$ and 60 cases with CEA $\geq 3.4 \mathrm{ng} / \mathrm{ml}$. With respect of tumor localization, 39 tumors were localized in $<6 \mathrm{~cm}$ and 73 localized in $>6 \mathrm{~cm}$ from the anal verge. There were 44 cases assessed as pathological T1-2 (pT1-2) while 68 cases as pathological T3-4 (pT3-4) and 67 patients assessed as stage pathological N0 (pN0) while 45 patients assessed as pathological $\mathrm{N}+(\mathrm{pN}+)$. A comparison of pretreatment staging results and histopathologic diagnosis after surgery revealed AJCC down-staging in $52.7 \%$ patients $(n=59)$. Tumor regression grade analysis showed good response (TRG 3 and TRG4) in 47.3\% patients $(\mathrm{n}=53)$.
Table 1 Correlations between EZH 2 expression and clinicopathological parameters

\begin{tabular}{|c|c|c|c|c|}
\hline \multirow{2}{*}{$\begin{array}{l}\text { Clinicopathological } \\
\text { parameters }\end{array}$} & \multirow{2}{*}{$\begin{array}{c}\text { Cases } \\
n=112\end{array}$} & \multicolumn{2}{|c|}{ EZH 2 expression } & \multirow{2}{*}{$\begin{array}{c}p \\
\text { value }\end{array}$} \\
\hline & & Low & High & \\
\hline \multicolumn{5}{|l|}{ Gender } \\
\hline Male & 71 & 32 & 39 & 0.530 \\
\hline Female & 41 & 21 & 20 & \\
\hline \multicolumn{5}{|l|}{ Age(years) } \\
\hline$<62$ & 49 & 26 & 23 & 0.283 \\
\hline$\geq 62$ & 63 & 27 & 36 & \\
\hline \multicolumn{5}{|l|}{ Histology } \\
\hline Differentiated & 64 & 36 & 28 & 0.029 \\
\hline Undifferentiated & 48 & 17 & 31 & \\
\hline \multicolumn{5}{|l|}{$\mathrm{CEA}(\mathrm{ng} / \mathrm{ml})$} \\
\hline$<3.4$ & 52 & 30 & 22 & 0.041 \\
\hline$\geq 3.4$ & 60 & 23 & 37 & \\
\hline \multicolumn{5}{|c|}{ Distance from anal verge $(\mathrm{cm})$} \\
\hline$<6$ & 39 & 20 & 19 & 0.539 \\
\hline$\geq 6$ & 73 & 33 & 40 & \\
\hline \multicolumn{5}{|l|}{ Clinical Tumor status } \\
\hline cT3 & 62 & 36 & 26 & 0.011 \\
\hline cT4 & 50 & 17 & 33 & \\
\hline \multicolumn{5}{|l|}{ Clinical Node status } \\
\hline cNO & 38 & 23 & 15 & 0.045 \\
\hline $\mathrm{cN}+$ & 74 & 30 & 44 & \\
\hline \multicolumn{5}{|l|}{ Ki-67 } \\
\hline Low & 56 & 42 & 14 & $<0.001$ \\
\hline High & 56 & 11 & 45 & \\
\hline
\end{tabular}

\section{Expression of EZH2 in LARC}

In this study, protein expression of EZH2 was examined by IHC(Figure 1). High expression of EZH2 was observed in 59/112 (52.7\%) biopsy specimens from patients underwent nCRT. The median Ki-67 expression is $37 \%$. The association between clinicopathological parameters and EZH2 expression levels were summarized in Table 1. EZH2 expression was significantly related to increased tumor cell proliferation, as assessed by Ki-67 expression with a cutoff value of $37 \%(p<0.001)$. High EZH2 expression was correlated closely with low differentiation $(\mathrm{p}=0.029)$, high CEA level $(p=0.041)$, T4 status $(\mathrm{p}=0.011)$ and Node metastasis $(\mathrm{p}=0.045)$.

\section{Correlation between EZH2 expression and CRT response}

To determine the ability of clinicopathological parameters to predict good histopathologic tumor response and down-staging to nCRT, the chi-square test was used (Table 2). It seemed that EZH2 low expression could predict the response to nCRT: 30 cases in 53 EZH2 low 


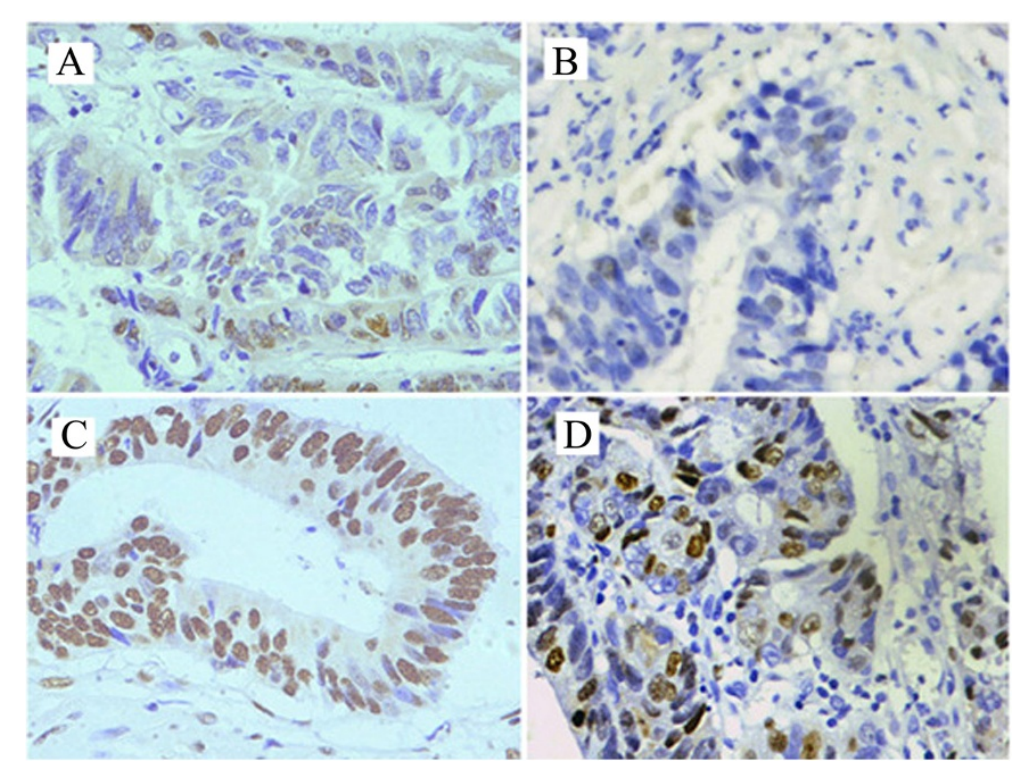

Figure 1 Immunohistochemical staining for EZH2 and Ki-67 in rectal cancer cell nucleus. A. Low expression of EZH2 (400X). B. Low expression of Ki-67 (400X). C. High expression of EZH2 (400X). D. High expression of Ki-67 (400X).

Table 2 Correlations between clinicopathological parameters and tumor response

\begin{tabular}{|c|c|c|c|c|c|c|c|}
\hline \multirow[t]{2}{*}{ Parameters } & \multirow{2}{*}{$\begin{array}{c}\text { Cases } \\
\mathrm{N}=112\end{array}$} & \multicolumn{2}{|c|}{ Tumor regression grade } & \multirow[t]{2}{*}{$p$ value } & \multicolumn{2}{|c|}{ Tumor } & \multirow[t]{2}{*}{$p$ value } \\
\hline & & Good response & Poor response & & Down-staging & Non-down-staging & \\
\hline \multicolumn{8}{|l|}{ Age } \\
\hline$<62$ & 49 & 24 & 25 & 0.519 & 26 & 23 & 0.943 \\
\hline$\geq 62$ & 63 & 27 & 36 & & 33 & 30 & \\
\hline \multicolumn{8}{|l|}{ Sex } \\
\hline Male & 71 & 34 & 37 & 0.511 & 41 & 30 & 0.157 \\
\hline Female & 41 & 17 & 24 & & 18 & 23 & \\
\hline \multicolumn{8}{|c|}{ Distance from anal verge $(\mathrm{cm})$} \\
\hline$<6$ & 39 & 18 & 21 & 0.924 & 23 & 16 & 0.329 \\
\hline$\geq 6$ & 73 & 33 & 40 & & 36 & 37 & \\
\hline \multicolumn{8}{|l|}{ Histology } \\
\hline Differentiated & 64 & 28 & 36 & 0.661 & 31 & 33 & 0.299 \\
\hline Undifferentiated & 48 & 23 & 25 & & 28 & 20 & \\
\hline \multicolumn{8}{|l|}{ CEA(ng/ml) } \\
\hline$<3.4$ & 52 & 30 & 22 & 0.016 & 33 & 19 & 0.033 \\
\hline$\geq 3.4$ & 60 & 21 & 39 & & 26 & 34 & \\
\hline \multicolumn{8}{|l|}{ Clinical Tumor status } \\
\hline сT3 & 62 & 35 & 27 & 0.01 & 37 & 25 & 0.099 \\
\hline cT4 & 50 & 16 & 34 & & 22 & 28 & \\
\hline \multicolumn{8}{|l|}{ Clinical Node status } \\
\hline $\mathrm{cNO}$ & 38 & 23 & 15 & 0.022 & 25 & 13 & 0.046 \\
\hline $\mathrm{cN}+$ & 74 & 28 & 46 & & 34 & 40 & \\
\hline \multicolumn{8}{|l|}{$\mathrm{EZH} 2$} \\
\hline Low & 53 & 30 & 23 & 0.026 & 34 & 19 & 0.021 \\
\hline High & 59 & 21 & 38 & & 25 & 34 & \\
\hline
\end{tabular}


expression patients achieved good tumor response while 21 cases in $59 \mathrm{EZH} 2$ high expression patients did ( $\mathrm{p}=$ 0.026); 34 cases in 53 EZH2 low expression patients achieved down-staging while 25 cases in 59 high expression patients did $(\mathrm{p}=0.021)$. Low CEA level and non node metastasis also showed significant correlation with good tumor regression $(\mathrm{p}=0.016$ and $\mathrm{p}=0.022)$ and down-staging $(\mathrm{p}=0.033$ and $\mathrm{p}=0.046)$. Tumors with cT3 were more likely to achieve good response than those with cT4 $(\mathrm{p}=0.01)$.

By multivariate stepwise logistic regression analysis, we found low expression of EZH2 showed significant correlation with good tumor regression $(\mathrm{OR}=2.684 ; 95 \% \mathrm{CI}$ 1.147-6.280, $\mathrm{p}=0.023)$ and down staging $(\mathrm{OR}=2.476$; 95\% CI 1.107-5.537, $\mathrm{p}=0.027)$. Moreover, cN was also kept in the model as a predictive factor for good tumor response $(\mathrm{p}=0.018)$ and down-staging $(\mathrm{p}=0.025)$ (Table 3$)$.

\section{Association of EZH 2 expression with Survival}

EZH2 status, cN, cT, pathological tumor status (pT) and pathological node status $(\mathrm{pN})$, were found to be significantly correlated with 5-year DFS and OS in univariate analysis. As listed in Table 4, among 112 patients who underwent nCRT, the 5-year DFS of 59 patients with EZH2 high expression was significantly poorer than that of 53 patients with EZH2 low expression $(\mathrm{p}=0.025)$ (Figure $2 \mathrm{~A})$. In the total study population, EZH2 high expression patients had significant poorer 5-year OS as compared with EZH2 low expression patients $(\mathrm{p}=0.032)$ (Figure $2 \mathrm{~B})$. In multivariate analysis, we found the $\mathrm{pN}$ was an important prognostic factor both for two end points while the $\mathrm{pT}$ was only the prognostic factor of 5-year DFS (Table 5). EZH2 was a prognostic factor for 5-year DFS $(\mathrm{HR}=2.287$; 95\% CI 1.137-4.602, $\mathrm{p}=0.020)$ but not for 5-year OS $(\mathrm{HR}=2.182 ; 95 \%$ CI 0.940-5.364, $\mathrm{p}=0.069)$ (Table 5).

\section{Discussion}

In this study, we first examined the expression of EZH2 in LARC and its predicting significance in 112 patients

Table 3 Multivariate analysis for tumor response

\begin{tabular}{llll}
\hline Parameters & Odds ratio & $\mathbf{9 5 \%}$ confidence interval & P value \\
\hline Good response & & & \\
CEA & 1.940 & $0.822-4.581$ & 0.130 \\
CT & 2.580 & $1.080-6.161$ & 0.033 \\
CN & 2.869 & $1.199-6.864$ & 0.018 \\
EZH2 & 2.684 & $1.147-6.280$ & 0.023 \\
Down-staging & & & 0.231 \\
CEA & 1.624 & $0.735-3.589$ & 0.025 \\
CN & 2.915 & $1.239-6.860$ & 0.027 \\
EZH2 & 2.476 & $1.107-5.537$ & \\
\hline
\end{tabular}

EZH2: Enhancer of zeste homologue 2; CEA: carcinoembryonic antigen.
Table 4 Univariate analysis between clinicopathological parameters and survival

\begin{tabular}{|c|c|c|c|c|c|}
\hline Parameters & Cases & $\begin{array}{c}\text { 5-year } \\
\text { DFS (\%) }\end{array}$ & $P$ value & $\begin{array}{l}\text { 5-year } \\
\text { OS(\%) }\end{array}$ & $P$ value \\
\hline \multicolumn{6}{|l|}{ Gender } \\
\hline Male & 71 & 62.8 & 0.631 & 76.7 & 0.354 \\
\hline Female & 41 & 64.4 & & 67.4 & \\
\hline \multicolumn{6}{|l|}{ Age } \\
\hline$<62$ & 49 & 64.2 & 0.615 & 69.9 & 0.476 \\
\hline$\geq 62$ & 63 & 62.7 & & 76.4 & \\
\hline
\end{tabular}

Distance from

anal verge $(\mathrm{cm})$

$\begin{array}{llllll}<6 & 39 & 59.9 & 0.375 & 68.4 & 0.286 \\ \geq 6 & 73 & 66.1 & & 76.7 & \\ \text { Histology } & & & & & \\ \quad \text { Differentiated } & 64 & 68.0 & 0.267 & 78.2 & 0.139 \\ \quad \text { Undifferentiated } & 48 & 56.3 & & 66.5 & \\ \text { CEA (ng/ml) } & & & & & \\ <3.4 & 52 & 68.2 & 0.320 & 77.0 & 0.380 \\ \geq 3.4 & 60 & 58.9 & & 66.7 & \end{array}$

Clinical Tumor status

$\begin{array}{llllll}\text { CT3 } & 62 & 70.0 & 0.046 & 81.4 & 0.021 \\ \text { CT4 } & 50 & 54.2 & & 59.4 & \end{array}$

Pathological Tumor status

pT0-2

$\begin{array}{llll}44 & 73.3 & 0.034 & 83.4\end{array}$

0.019

pT3-4

$68 \quad 56.8$

65.3

Clinical Node status

$\begin{array}{llllll}\text { cNO } & 38 & 78.6 & 0.011 & 84.0 & 0.008 \\ \text { CN+ } & 74 & 51.9 & & 59.5 & \end{array}$

Pathological Node status

$\begin{array}{cccccc}\text { pNo } & 67 & 69.4 & 0.016 & 79.9 & 0.024 \\ \text { pN+ } & 45 & 54.5 & & 61.7 & \\ \text { ZH 2 } & & & & & \\ \text { High } & 53 & 74.0 & 0.025 & 82.8 & 0.032 \\ \text { Low } & 59 & 53.8 & & 64.1 & \end{array}$

DFS: Disease free survival; OS:overall survival.

treated with nCRT. Our results showed that the high expression of EZH2 correlated with undifferentiation, high CEA level, T4 status and lymph node metastasis status at diagnosis. By univariate and multivariate analysis, we observed low expression of EZH2 showed significant correlation with good tumor regression $(p=0.026)$ and down-staging $(\mathrm{p}=0.021)$, which means EZH2 can reliably and independently predict the response to $\mathrm{nCRT}$ with LARC.

The results from the current study are in accordance with the previous studies in other solid cancers [11,17]. In esophageal squamous cell carcinoma (ESCC), high 


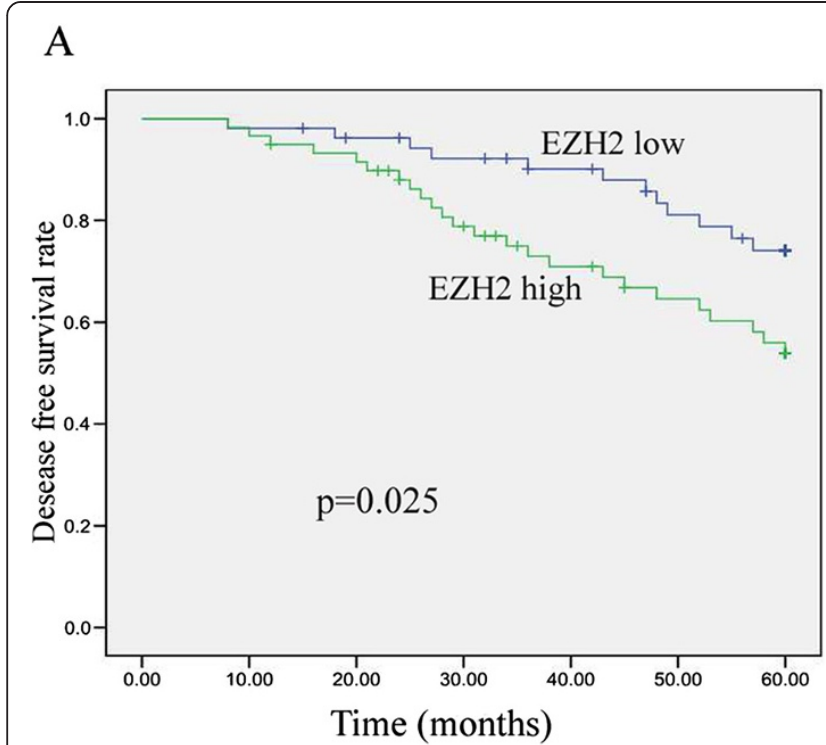

\section{B}

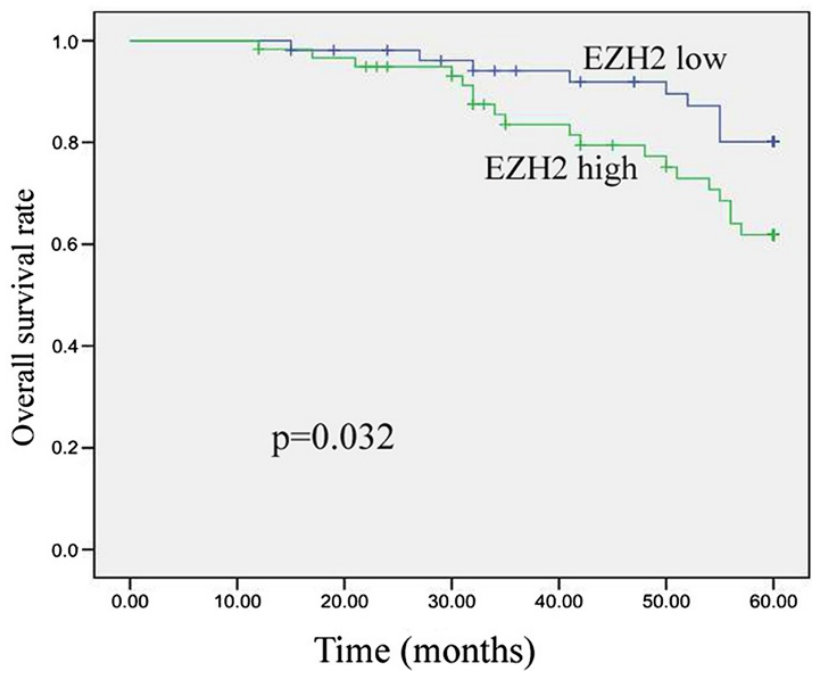

Figure 2 Kaplan-Meier estimates of disease-free survival(DFS) and overall survival (OS) rates in relation to EZH2 expression. A. The 5 -year DFS was significantly shorter in patients with high expression patients than in patients with low expression $(p=0.025)$. B. The 5-year OS was significantly shorter in patients with high expression patients than in patients with low expression $(p=0.032)$.

EZH2 expression was significantly correlated with increased cell proliferation $(\mathrm{p}=0.009)$ and lack of clinical complete response to CRT $(\mathrm{p}=0.028)$ [11]. Pharmacologic inhibition of EZH2 suppressed cell growth and increased radiation sensitivity of ATRT cells [16]. In lung cancer, EZH2 silencing with RNA interference (RNAi) enhances A549 and HTB-56 cell sensitivity to irradiation both in vitro and in vivo [23].

The sensitivity of chemotherapy and/or radiotherapy is a complex phenomenon and regulated by a series of internal and extrinsic factors, including cell cycle arrest, cell apoptosis, and DNA damage repair [24]. There are two mechanisms possibly associated with resistance to CRT of high EZH2 expression. First, EZH2 is a cell cycle regulator [14]. A cDNA microarray study demonstrated that disruption of EZH2 expression can retard cell proliferation [25]. It is a fact that cells are not equally sensitive to radiation throughout the cell cycle but show

Table 5 Multivariate analysis for survival

\begin{tabular}{llll}
\hline Parameters & Hazard ratio & 95\% confidence interval & P value \\
\hline 5-year-DFS & & & \\
EZH2 & 2.287 & $1.137-4.602$ & 0.020 \\
pT & 2.244 & $1.076-4.678$ & 0.013 \\
pN & 2.532 & $1.292-4.961$ & 0.007 \\
5-year-OS & & & \\
EZH2 & 2.182 & $0.940-5.064$ & 0.069 \\
pT & 2.395 & $0.997-5.365$ & 0.051 \\
pN & 2.471 & $1.138-5.364$ & 0.022 \\
\hline
\end{tabular}

increased radiation sensitivity in G2/M phase and decreased radiation sensitivity in $\mathrm{S}$ phase. Over-expression of EZH2 was observed to shorten the G1 phase of the cell cycle and lead to accumulation of cells in the $\mathrm{S}$ phase [15]. Inhibition of EZH2 by interfering RNA (RNAi) led to significant inhibition of DNA synthesis and increased the percentage of ATRT cells in G2/M phase [16]. EZH2 might be responsible, at least in part, for the tumor resistance to radiotherapy [11]. Second, as an essential downstream target of $\mathrm{pRB} / \mathrm{E} 2 \mathrm{~F}$ pathway, EZH2 is a critical mediator of E2F function [15]. E2F1 has been observed to be associated with radiosensitivity and/or chemosensitivity in certain types of tumors [17-19]. Thus, the pRB/E2F/EZH2 pathway may be one of the mechanisms involved in tumor response to CRT.

EZH2 high expression has been studied in many solid tumors [8-13]. But up to now only one report studied EZH2 expression in 409 colorectal cancer patients but found no association between EZH2 expression and prognosis in rectal cancer [26]. In this study we first showed the significant correlation between EZH2 high expression and poor prognosis in LARC. The differences can be explained in two aspects: First, the above study used the resected tissue while our study used biopsy tissues. Second, the patients in the above study took surgery directly while the patients of this study received concurrent chemotherapy and radiotherapy followed by surgery.

In our study, EZH2 over-expression could be a valuable prognostic indicator of poor 5-year DFS both in univariate and multivariate analyses. Refers to 5-year 
OS, in univariate analysis, EZH2 over-expression could predict poor outcome but there is no significant difference in multivariate analysis. Although the difference was not significantly, it still revealed a trend the EZH2 over expression showed shorter 5-year OS $(\mathrm{p}=0.069)$.

The similar results were also observed in other solid tumors [8-13]. In metastatic prostate cancer, EZH2 upregulated oncogenes and loss of EZH2 inhibited the proliferation of cancer cells $[8,19]$. In breast cancer, abnormally elevated EZH2 levels have been found to be highly correlated with tumor cell invasiveness and increased proliferation rates, poor prognosis $[27,28]$. In ESCC, high expression of EZH2 was also observed to be an independent prognostic factor [11].

The possible mechanisms underlying associations of high expression of EZH2 and the poor prognosis is very complexed. The functional consequence of increased EZH2 expression in cancer tissues includes the silencing of genes that promote differentiation and restrain proliferation [29]. Currently, EZH2 has been found to function as a transcriptional repressor that silences an array of target genes, including more than 200 tumor suppressors [30]. In addition to its role as a transcriptional repressor, several studies have shown that EZH2 may also function in target gene activation [31-33]. Furthermore, overexpression of EZH2 is involved in many signaling pathways, such as the pRB-E2F, PI3K/Akt, estrogen receptor and c-Myc signal transduction pathways $[8,15,25,27,34]$. These results collectively, suggest that EZH2 high expression were significantly associated with tumor invasiveness and poor prognosis, the regulation of protein expression of EZH2 is quite complicated, and it may be a promising candidate for anti-cancer treatment.

\section{Conclusion}

In this study, we observed, for the first time, EZH2 expression in LARC could predict the response to nCRT. EZH2 high expression were significantly associated with shorter 5-year disease-free survival and 5-year overall survival in univariate analysis. However, some inherent limitations of this study might lead to biased results. First, the current study was a retrospective study and the number of patients in our study was limited. Second, the chemotherapeutic regimens were various, which could affect the tumor response to nCRT [35]. Third, for tumor heterogeneity, weather a biopsy is representative of the whole tumor need to be investigated. To further validate the role of EZH2 in rectal cancer, large consistent cohort studies are needed.

\footnotetext{
Abbreviations

LARC: Locally advanced rectal cancer; nCRT: Neoadjvant chemoradiotherapy; EZH2: Enhancer of zeste homologue 2; IHC: Immunohistochemistry; EGFR: Epidermal growth factor receptor; VEGF: Vascular endothelial growth factor; TNM: Tumor-node-metastasis; CEA: Carcinoembryonic antigen;
}

CT: Computed tomography; MRI: Magnetic resonance imaging; AJCC: American Joint Committee on Cancer; TME: Total mesorectal excision; TRG: Tumor regression grade; DAB: 3,3'-diaminobenzidine; OS: Overall survival; DFS: Disease free survival; SPSS: Statistical Product and Service Solutions; ESCC: Esophageal squamous cell carcinoma; ATRT: Atypical rhabdoid teratoid tumor; cT: Clinical tumor; cN: Clinical node status; pT: Pathological tumor; pN: Pathological node status.

\section{Competing interests}

The authors declare that they have no competing interests.

\section{Authors' contributions}

$\mathrm{XM}$ and $\mathrm{ZH}$ made equal contributions. They drafted the manuscript and carried out the immunohistochemistry. RW participated in the design of the study. YJ collected the materials of the patients. HL performed the statistical analysis. XX collected the patient materials. RF drafted the manuscript. KZ performed the statistical analysis. SJ and HY helped to collected the materials of the patients and draft the manuscript. JY conceived of the study, and participated in its design and coordination. All authors read and approved the final manuscript.

\section{Acknowledgments}

The work was supported by National Natural Science Foundation of China (No. 81301868) and by Shandong province science and technology development program (No. 2012 YD18086 and 2012YD18053).

\section{Author details}

${ }^{1}$ Department of Radiation Oncology of Shandong Cancer Hospital and Institute, No. 440 Jiyan Road, Jinan, Shandong 250117, China. ${ }^{2}$ Department of Radiology, Provincial Hospital Affiliated to Shandong University, Jinan, Shandong 250021, China. ${ }^{3}$ Department of Medicine of Shandong Cancer Hospital and Institute, Jinan, Shandong 250117, China.

Received: 31 May 2014 Accepted: 18 August 2014

Published: 27 August 2014

\section{References}

1. Jemal A, Bray F, Center MM, Ferlay J, Ward E, Forman D: Global cancer statistics. CA Cancer J Clin 2011, 61:69-70.

2. van Gijn W, Marijnen CA, Nagtegaal ID, Kranenbarg EM, Putter H, Wiggers T, Rutten HJ, Påhlman L, Glimelius B, van de Velde CJ: Preoperative radiotherapy combined with total mesorectal excision for resectable rectal cancer: 12-Year follow-up of the multicentre, randomised controlled TME trial. Lancet Oncol 2011, 12:575-582.

3. Roh MS, Colangelo LH, O'Connell MJ, Yothers G, Deutsch M, Allegra CJ, Kahlenberg MS, Baez-Diaz L, Ursiny CS, Petrelli NJ, Wolmark N: Preoperative multimodality therapy improves disease-free survival in patients with carcinoma of the rectum: NSABP R-03. J Clin Oncol 2009, 27:5124-5130.

4. Sauer R, Becker H, Hohenberger W, Rödel C, Wittekind C, Fietkau R, Martus P, Tschmelitsch J, Hager E, Hess CF, Karstens JH, Liersch T, Schmidberger H, Raab R, German Rectal Cancer Study Group: Preoperative versus postoperative chemoradiotherapy for rectal cancer. N Engl J Med 2004, 351:1731-1740.

5. Kapiteijn E, Marijnen CA, Nagtegaal ID, Putter H, Steup WH, Wiggers T, Rutten HJ, Pahlman L, Glimelius B, van Krieken JH, Leer JW, van de Velde CJ, Dutch Colorectal Cancer Group: Preoperative radiotherapy combined with total mesorectal excision for resectable rectal cancer. N Engl J Med 2001, 345:638-646.

6. Collett K, Eide GE, Arnes J, Stefansson IM, Eide J, Braaten A, Aas T, Otte AP, Akslen LA: Expression of enhancer of zeste homologue 2 is significantly associated with increased tumor cell proliferation and is a marker of aggressive breast cancer. Clin Cancer Res 2006, 12:1168-1174.

7. Cardoso C, Mignon C, Hetet G, Grandchamps B, Fontes M, Colleaux L: The human EZH2 gene: genomic organization and revised mapping in $7 \mathrm{q} 35$ within the critical region for malignant myeloid disorders. Eur $J$ Hum Genet 2000, 8:174-180.

8. Varambally S, Dhanasekaran SM, Zhou M, Barrette TR, Kumar-Sinha C, Sanda MG, Ghosh D, Pienta KJ, Sewalt RG, Otte AP, Rubin MA, Chinnaiyan AM: The polycomb group protein EZH2 is involved in progression of prostate cancer. Nature 2002, 419:624-629. 
9. Raman JD, Mongan NP, Tickoo SK, Boorjian SA, Scherr DS, Gudas LJ: Increased expression of the polycomb group gene. EZH2, in transitional cell carcinoma of the bladder. Clin Cancer Res 2005, 11:8570-8576.

10. Kidani K, Osaki M, Tamura T, Yamaga K, Shomori K, Ryoke K, Ito H: High expression of $\mathrm{EZH} 2$ is associated with tumor proliferation and prognosis in human oral squamous cell carcinomas. Oral Oncol 2009, 45:39-46.

11. He LR, Liu MZ, Li BK, Jia WH, Zhang Y, Liao YJ, Chen YC, Zhang LJ, Guan XY, Zeng $Y X$, Kung HF, Xie D: High expression of EZH2 is associated with tumor aggressiveness and poor prognosis in patients with esophageal squamous cell carcinoma treated with definitive chemoradiotherapy. Int J Cancer 2010, 127:138-147.

12. Roh S, Park SY, Ko HS, Sohn JS, Cha EJ: EZH2 expression in invasive lobular carcinoma of the breast. World J Surg Oncol 2013, 11:299.

13. Xu L, Deng Q, Pan Y, Peng M, Wang X, Song L, Xiao M, Wang Z: Cancerassociated fibroblasts enhance the migration ability of ovarian cancer cells by increasing EZH2 expression. Int J Mol Med 2014, 33:91-96.

14. Lee TI, Jenner RG, Boyer LA, Guenther MG, Levine SS, Kumar RM, Chevalier B, Johnstone SE, Cole MF, Isono K, Koseki H, Fuchikami T, Abe K, Murray HL, Zucker JP, Yuan B, Bell GW, Herbolsheimer E, Hannett NM, Sun K, Odom DT, Otte AP, Volkert TL, Bartel DP, Melton DA, Gifford DK, Jaenisch R, Young RA: Control of developmental regulators by Polycomb in human embryonic stem cells. Cell 2006, 125:301-313.

15. Bracken AP, Pasini D, Capra M, Prosperini E, Colli E, Helin K: EZH2 is downstream of the pRB-E2F pathway, essential for proliferation and amplified in cancer. EMBO J 2003, 22:5323-5335.

16. Alimova I, Birks DK, Harris PS, Knipstein JA, Venkataraman S, Marquez VE, Foreman NK, Vibhakar R: Inhibition of EZH2 suppresses self-renewal and induces radiation sensitivity in atypical rhabdoid teratoid tumor cells. Neuro Oncol 2013, 15:149-160.

17. Laitinen S, Martikainen PM, Tolonen T, Isola J, Tammela TL, Visakorpi T: $\mathrm{EZH} 2, \mathrm{Ki}-67$ and MCM7 are prognostic markers in prostatectomy treated patients. Int J Cancer 2008, 122:595-602.

18. Berton TR, Mitchell DL, Guo R, Johnson DG: Regulation of epidermal apoptosis and DNA repair by E2F1 in response to ultraviolet B radiation. Oncogene 2005, 24:2449-2460.

19. Benadiba M, Miyake JA, Colquhoun A: Gamma-linolenic acid alters Ku80. $\mathrm{E} 2 \mathrm{~F} 1$, and bax expression and induces micronucleus formation in $\mathrm{C} 6$ glioma cells in vitro. IUBMB Life 2009, 61:244-251.

20. Sobin LH, Compton CC: TNM seventh edition: what's new, what's changed: communication from the international union against cancer and the american joint committee on cancer. Cancer 2010, 116:5336-5339.

21. Dworak O, Keilholz L, Hoffmann A: Pathological features of rectal cancer after preoperative radiochemotherapy. Int J Colorectal Dis 1997, 12:19-23.

22. Matsukawa $Y$, Semba S, Kato H, Ito A, Yanagihara K, Yokozaki H: Expression of the enhancer of zeste homolog 2 is correlated with poor prognosis in human gastric cancer. Cancer Sci 2006, 97:484-491.

23. Xia H, Yu CH, Zhang Y, Yu J, Li J, Zhang W, Zhang B, Li Y, Guo N: EZH2 silencing with RNAi enhances irradiation-induced inhibition of human lung cancer growth in vitro and in vivo. Oncol Lett 2012, 4:135-140.

24. Horsman MR, Bohm L, Margison GP, Milas L, Rosier JF, Safrany G, Selzer E, Verheij M, Hendry JH: Tumor radiosensitizers-current status of development of various approaches: report of an International Atomic Energy Agency meeting. Int J Radiat Oncol Biol Phys 2006, 64:551-561.

25. Tang X, Milyavsky M, Shats I, Erez N, Goldfinger N, Rotter V: Activated p53 suppresses the histone methyltransferase EZH2 gene. Oncogene 2004 23:5759-5769.

26. Fluge $\varnothing$, Gravdal K, Carlsen E, Vonen B, Kjellevold K, Refsum S, Lilleng R, Eide TJ, Halvorsen TB, Tveit KM, Otte AP, Akslen LA, Dahl O, Norwegian Gastrointestinal Cancer Group: Expression of EZH2 and Ki-67 in colorectal cancer and associations with treatment response and prognosis. $\mathrm{Br} J$ Cancer 2009, 101:1282-1289.

27. Deb G, Thakur VS, Gupta S: Multifaceted role of EZH2 in breast and prostate tumorigenesis: epigenetics and beyond. Epigenetics 2013, 8:464-476.

28. Bachmann IM, Halvorsen OJ, Collett K, Stefansson IM, Straume O, Haukaas $\mathrm{SA}$, Salvesen HB, Otte AP, Akslen LA: EZH2 expression is associated with high proliferation rate and aggressive tumor subgroups in cutaneous melanoma and cancers of the endometrium, prostate, and breast. J Clin Oncol 2006, 24:268-273.

29. Tan JZ, Yan Y, Wang XX, Jiang Y, Xu HE: EZH2: biology, disease, and structure-based drug discovery. Acta Pharmacol Sin 2014, 35:161-174.
30. O'Meara MM, Simon JA: Inner workings and regulatory inputs that control Polycomb repressive complex 2. Chromosoma 2012, 121:221-234.

31. Yap DB, Chu J, Berg T, Schapira M, Cheng SW, Moradian A, Morin RD, Mungall AJ, Meissner B, Boyle M, Marquez VE, Marra MA, Gascoyne RD, Humphries RK, Arrowsmith CH, Morin GB, Aparicio SA: Somatic mutations at EZH2 Y641 act dominantly through a mechanism of selectively altered PRC2 catalytic activity, to increase H3K27 trimethylation. Blood 2011, 117:2451-2459.

32. McCabe MT, Graves AP, Ganji G, Diaz E, Halsey WS, Jiang Y, Smitheman KN, Ott HM, Pappalardi MB, Allen KE, Chen SB, Della Pietra A III, Dul E, Hughes AM, Gilbert SA, Thrall SH, Tummino PJ, Kruger RG, Brandt M, Schwartz B, Creasy CL: Mutation of $\mathrm{A} 677$ in histone methyltransferase $\mathrm{EZH} 2$ in human B-cell lymphoma promotes hypertrimethylation of histone $\mathrm{H} 3$ on lysine 27 (H3K27). Proc Natl Acad Sci U S A 2012, 109:2989-2994.

33. Lee ST, Li Z, Wu Z, Aau M, Guan P, Karuturi RK, Liou YC, Yu Q: Context-specific regulation of NF-kappaB target gene expression by EZH2 in breast cancers. Mol Cell 2011, 43:798-810.

34. Shi B, Liang J, Yang X, Wang Y, Zhao Y, Wu H, Sun L, Zhang Y, Chen Y, Li R, Zhang $Y$, Hong $M$, Shang $Y$ : Integration of estrogen and Wnt signaling circuits by the polycomb group protein EZH2 in breast cancer cells. Mol Cell Biol 2007, 27:5105-5119.

35. Sanghera P, Wong DW, McConkey CC, Geh Il, Hartley A: Chemoradiotherapy for rectal cancer: an updated analysis of factors affecting pathological response. Clin Oncol (R Coll Radiol) 2008, 20:176-183.

doi:10.1186/1748-717X-9-188

Cite this article as: Meng et al:: The prognostic role of EZH2 expression in rectal cancer patients treated with neoadjuvant chemoradiotherapy. Radiation Oncology 2014 9:188.

\section{Submit your next manuscript to BioMed Central and take full advantage of:}

- Convenient online submission

- Thorough peer review

- No space constraints or color figure charges

- Immediate publication on acceptance

- Inclusion in PubMed, CAS, Scopus and Google Scholar

- Research which is freely available for redistribution 